\title{
ADJUNCTIVE USE OF PLASMA RICH IN GROWTH FACTORS FOR IMPROVING ALVEOLAR SOCKET HEALING: A SYSTEMATIC REVIEW
}

\author{
$2^{8} \Lambda^{M A S S I M O ~ D E L ~ F A B B R O, ~ M S c, ~ P h D ~}{ }^{a, b},{ }_{1}$ SOURAV PANDA, MDS ${ }^{a, c}$, AND \\ \&1 $\mathrm{S}^{\mathrm{S}}$ ILVIO TASCHIER/, MD, DDS ${ }^{\mathrm{a}, \mathrm{b}, \mathrm{d}}$ \\ aDipartimento di Scienze Biomediche, Chirurgiche e Odontoiatriche, Università degli Studi di Milano, Milano, Italy \\ b.R.C.C.S. Istituto Ortopedico Galeazzi, Milano, Italy \\ 'Department of Periodontics and Oral Implantology, Institute of Dental Science and SUM Hospital, Siksha O Anusandhan, Bhubaneswar, India
}

\section{ABSTRACT}

\section{Purpose}

The purpose of this study was to determine whether the adjunctive use of plasma rich in growth factors in postextraction sites could be beneficial in terms of hard-I 22 soft-tissue healing and patients' comfort.

Materials and Methods

An electronic search was performed on MEDLINE, EMBASE, Scopus, and CENTRAL. Only controlled clinical trials or randomized clinical trials that used plasma rich in growth factors in the test group were included. The primary outcomes were pain assessment, complications, and adverse events. Secondary outcomes were hard-tissue healing, bone remodeling, and soft-tissue healing.

Results

Eight comparative studies (5 randomized clinical trials) were included. Four studies had a split-mouth design. Six hundred fourteen teeth were extracted in 338 patients. Only qualitative analysis could be performed. Postoperative pain and the incidence of complications such as alveolar osteitis were consistently lower in the test group. Hard-tissue healing, evaluated by clinical, radiographic, histologic, and histomorphometric techniques, showed significantly better results for the test group in almost all studies. Better epithelialization, keratinized tissue thickness, and healing score were also reported.

\section{Conclusion}

Plasma rich in growth factors may bring advantages in some relevant clinical and radiographic outcomes, such as bone density and soft-tissue healing, after tooth extraction. It could also represent a useful tool for reducing adverse events, complications, and patients' discomfort, although it is still not quantifiable.

\section{INTRODUCTION}

Toin ooth extraction, in routine dental practice, is carried out for the tooth with hopeless prognosis affected by deep dental caries, periodontitis, or trauma or sometimes as a treatment protocol for orthodontic space creation. ${ }^{1}$ The physiological process of postextraction alveolar socket healing involves a complex and intricate play of bone cell migration and maturation along
CORRESPONDING AUTHOR:

Massimo Del Fabbro, Università degli Studi di Milano, I.R.C.C.S. Istituto Ortopedico Galeazzi, Via Riccardo Galeazzi 4, 20161 Milano, Italy.

E-mail: massimo.delfabbro@unimi.it

KEYWORDS

Platelet rich in growth factors, Postextraction healing, Systematic review

Source of Funding: Not reported.

Conflict of interest: The authors have no actual or potential conflicts of interest.

Received 19 September 2018; revised 13 November 2018; accepted 19 November 2018

J Evid Base Dent Pract 2019: [1-11]

1532-3382/\$36.00

(c) 2018 Elsevier Inc.

All rights reserved.

doi: https://doi.org/10.1016/

j.jebdp.2018.11.003 
with selective bone resorption and apposition. ${ }^{2}$ These healing events are rather complicated and delayed, in various situations, leading to vertical and/or horizontal decrease of alveolar process dimension. During the healing period, some complications, such as alveolar osteitis (AO), bleeding, intense pain, infection, and trismus or swelling, associated with postextraction sites may arise. $^{3}$ Nonetheless, inadequate bone apposition or progressive bone resorption may occur, compromising the placement of implant-supported prosthetic rehabilitation. Bone loss and changes in the soft-tissue profile resulting from tooth loss and an unpleasant esthetic aspect can also hinder rehabilitation of the edentulous ridge using removable or fixed prostheses. ${ }^{4}$

The concept of "socket preservation" with various biomaterials is used in postextraction sites to hinder the alveolar process dimensional reduction and lessen the healing complications. Various systematic reviews indicate the use of biomaterials, such as bone substitutes, collagen sponges, barrier membranes, and growth factors, in the postextraction sites and have proven their efficacy on the basis of some clinical evidence..$^{5-9}$ Moreover, these preservation techniques may avoid additional bone augmentation at the time of implant rehabilitation. However, the efficacy of these alveolar socket-preservation treatments is still unclear. In a recent systematic review, it was concluded that the alveolar ridge resorption cannot be totally avoided; rather, it can be prevented with the use of such preservation techniques, although no specific technique is proved to be superior than the others. ${ }^{10}$

Previous clinical research on the use of different biomaterials, such as particulate hydroxyl-apatite, ${ }^{11}$ bio-active glass, ${ }^{12}$ polylactide/polyglycolic sponges, ${ }^{13}$ barrier membranes, ${ }^{14}$ and others, for socket preservation has been documented. ${ }^{15}$ The origin of these biological materials is rather heterogeneous, and the cost of manufacturing processes to make them compatible for use in human applications often translates into an economic burden for patients. In addition, some patients reject the use of xenografts or allografts, arguing that they are afraid of the possibility of disease transmission from the donor, while others refuse autologous bone grafts because of the fear of pain and discomfort due to the harvesting procedure. ${ }^{16}$ It has also been demonstrated that some graft materials are not completely degraded many years after implantation and only slightly promote osteogenic induction, ${ }^{17}$ which also directly affects the formation of new bone and soft-tissue healing in the tooth-extraction sockets.

The use of biologic agents such as recombinant human bone morphogenetic protein-2, basic fibroblast growth factors, recombinant human platelet-derived growth factor, and transforming growth factor beta had proven to promote osteogenic induction in cases of alveolar socket preservation in recent studies. ${ }^{18,19}$ In addition, the use of autologous platelet concentrates (APCs) is gaining popularity as a source of a number of growth factors in high concentrations, for regenerative treatments in many clinical applications. The contribution of blood-derived platelets to the bone-healing process is thought to be based on the growth factors stored in their granules and released on activation. APCs are advantageously used as a cost-effective adjunct to surgical regenerative therapy, even in combination with bone grafts. ${ }^{20}$ Several systematic reviews have reported on the efficacy of the use of these APCs in postextraction sites, suggesting improvement of postoperative soft-tissue healing, control of postoperative symptoms, and adequate socket preservation. ${ }^{21-24}$

Plasma rich in growth factors (PRGF) is a biological concept developed and introduced at the end of the 1990s. ${ }^{25}$ Among the various types of APCs, PRGF is characterized by a relatively modest increase of the concentration of platelets (2-3 times the serum platelet concentration), with respect to platelet-rich plasma (5-8 times), and by the absence of leukocytes. ${ }^{26}$ The increased concentration of platelets delivers a wide array of platelet growth factors, which may promote osteogenic induction and may simultaneously facilitate soft-tissue healing in the postextraction sites. Various clinical trials have reported the use of PRGF in wound healing and preservation of postextraction sites. ${ }^{25,27-30}$ However, no systematic review has been published to date that evaluates the scientific quality of these trials and the consistency among studies regarding the effect of using PRGF in postextraction sites. The aim of this systematic review is to investigate whether PRGF is effective in the preservation of the postextraction alveolus.

\section{MATERIALS AND METHODS}

This systematic review was conducted based on Preferred Reporting Items for Systematic Reviews and Meta-analysis guidelines. ${ }^{31}$ The review protocol was registered on the International Prospective Register of Systematic Reviews (PROSPERO, no.: CRD42018091547).

\section{Research Question}

The research question was "Is the adjunctive use of PRGF in postextraction sites beneficial in terms of hard-/soft-tissue healing and patients' comfort?"

\section{Search Strategy}

An electronic search was carried out in the following databases: MEDLINE, Cochrane Central Register of Controlled Trials (CENTRAL), SCOPUS, and EMBASE, using a series of search terms combined with the Boolean operators "AND," "OR," and "NOT." The search string was designed using the following keywords: (plasma OR plasma rich in growth factors OR PRGF OR pure platelet rich plasma OR P-PRP OR 
endoret) AND (post extraction sites OR extraction socket healing $O R$ socket preservation $O R$ tooth extraction $O R$ third molar extraction OR third molar surgery). The last electronic search was carried out on March 2018. In addition, a hand search was performed in the following dental journals: British Dental Journal, British Journal of Oral and Maxillofacial Surgery, Clinical Implant Dentistry and Related Research, Clinical Oral Implants Research, Clinical Oral Investigations, European Journal of Oral Implantology, European Journal of Oral Sciences, Implant Dentistry, International Journal of Oral and Maxillofacial Implants, International Journal of Oral and Maxillofacial Surgery, International Journal of Periodontics and Restorative Dentistry, Journal of Clinical Periodontology, Journal of Dental Research, Journal of Dentistry, Journal of Implantology, Journal of Maxillofacial and Oral Surgery, Journal of Oral and Maxillofacial Surgery, Journal of Periodontal Research, Journal of Periodontology, and Oral Surgery, Oral Medicine, Oral Pathology, Oral Radiology. The bibliographies of the included studies and of the reviews were also searched for possible additional eligible studies. Finally, we searched the following trial registries for ongoing studies: US National Institutes of Health Ongoing Trials Register ClinicalTrials.gov (clinicaltrials.gov; searched on February 20, 2017) and World Health Organization International Clinical Trials Registry Platform (apps.who.int/trialsearch; searched on February 20, 2018).

\section{Inclusion Criteria}

The inclusion criteria for the eligible studies were as follows:

- The study had to be a comparative prospective clinical trial (randomized or controlled) with parallel or splitmouth design involving postextraction sites in human subjects. Both single and multiple extraction sites were considered.

- The study had to use PRGF alone or in adjunct to any grafting material (eg, bone substitutes) in the experimental group, and the only difference to the control group had to be the use of PRGF.

- Studies with patients with systemic illness, with smoking habits, or who underwent radiotherapy were included in this review.

- No restriction on the language, sample size, follow-up duration, or year of publication was applied.

\section{Study Selection and Data Collection}

Two independent reviewers (S.P. and M.D.F.) screened the title and abstract of the articles retrieved from the electronic search, based on the set of inclusion criteria. The full text of the relevant eligible studies was further assessed independently by the same 2 reviewers to ensure that the studies met the inclusion criteria. The disagreements between the reviewers were resolved by discussion, and the reasons for exclusion were recorded for each excluded study.

Relevant data of the included studies were extracted using an Excel spreadsheet (Microsoft, Redmond, WA).

The primary outcomes evaluated were

- Postoperative pain (measured with a visual analog scale)

- Any adverse effects/complications such as infection, swelling, alveolitis, $\mathrm{AO}$, or any type of symptoms in the postoperative period.

The secondary outcomes evaluated were

- Assessment of hard-tissue healing (by radiographic or histomorphometric analysis)

- Clinical or radiographic evaluation of marginal bone remodeling (eg, bone height at the vestibular and lingual or palatal aspect and bone width at the extraction region)

- Assessment of soft-tissue healing (using the healing index proposed by Landry or other standard indexes)

Risk of Bias Assessment

Risk of bias (RoB) was assessed by two independent reviewers (S.P. and M.D.F.) for all the included clinical trials, and the discrepancies were resolved by discussion and in consent with a third reviewer (S.T.). The assessment was carried out using parameters such as random sequence generation, allocation concealment, blinding of outcome assessment, comparability of control and treatment groups at entry, clear definition of inclusion and exclusion criteria, clear definition of outcome assessment, completeness of outcome data reporting, recall rate, sample size calculation, and the number of surgeons involved. The criteria of RoB assessment were modified from the guidelines reported in the Cochrane Handbook for Systematic Reviews of Interventions, version 5.1.0.

The summary of the RoB assessment of the studies was validated by grading them into high, medium, or low risk. A study was considered to be at high risk if it was found to have two or more of the assessed parameters classified at high risk or one parameter at high risk and three or more at uncertain risk; it was considered to be at medium risk if one of the parameters was classified at high risk and no more than two at uncertain risk; and it was considered to be at low risk if none of the parameters was classified at high risk and no more than three at uncertain risk.

Data Analysis

The data from different studies were combined by metaanalysis only when at least two studies with similar 
comparisons were found, reporting the same outcome measurements at comparable observation times after tooth extraction. For each trial, for dichotomous outcomes (such as postoperative $\mathrm{AO}$ recorded as yes or no), the estimation of the effect of an intervention is expressed as risk ratios with 95\% confidence intervals (Cls). For continuous outcomes (such as percentage of newly formed bone and alveolar bone height and width changes), mean differences with 95\% $\mathrm{Cls}$ were used to synthesize data for each treatment group. The statistical analysis unit was, if possible, the patient, unless all compared studies expressed the results using the tooth as the unit of analysis. If a meta-analysis could not be performed for a given outcome, then a qualitative report of the results is provided. Risk ratios for dichotomous data and mean differences for continuous data were combined using random-effects models if at least 4 studies could be included in the meta-analysis; otherwise, a fixed-effects model was adopted. Review Manager 5.3 (The Nordic Cochrane Center, The Cochrane Collaboration, Copenhagen, Denmark) was used for meta-analysis calculations and graphs.

\section{RESULTS}

The electronic search retrieved a total of 694 articles. After discarding the duplicates, unrelated records, and articles excluded for specific reasons, 8 studies were included for qualitative analysis in this review (Figure 1). ${ }^{25,27-30,32-34}$

The main features of the included studies are summarized in Tables 1 and 2. The excluded studies are listed in Table 3, with reasons for their exclusion. ${ }^{35-41}$

\section{Primary Outcomes}

\section{Postoperative Pain}

Five out of 8 studies evaluated postoperative pain for a follow-up duration of 7 days. ${ }^{27-29,33,34}$ The studies reveal that postoperative pain was comparatively lesser in the postextraction sites treated with PRGF than the control sites. Postoperative pain was almost absent in the PRGF-treated sites in one of the studies, ${ }^{27}$ having the scores of 0.17 and 0.00 at day $3(P<.001)$ and day $7(P<.03)$, respectively (Table 4).

\section{Adverse Events/Complications}

In one of the included trials that had the occurrence of $A O$ as the primary outcome, lower incidence of $A O$ and acute inflammation was documented in the PRGF-treated sites than in control sites. ${ }^{29}$ In the split-mouth study, 18 of 40 patients presented with $A O$ in the control sites, whereas only 4 cases of $A O$ occurred in the sites treated with PRGF in patients who also developed $\mathrm{AO}$ on the control site. ${ }^{29}$

In another study, PRGF was as effective as fibrin glue for prevention of severe bleeding in patients with blood coagulopathies and thrombocytopenia. ${ }^{32}$

\section{Figure 1. Flow diagram of the study selection process.}

\section{Hard-tissue Healing}

The included trials have evaluated hard-tissue healing under a variety of assessments such as clinical, radiological, histologic, and histomorphometric analyses.

Residual socket volume (RSV) was the parameter used to clinically assess hard-tissue healing in two studies ${ }^{28,33}$ and was found to be better in the sites treated with PRGF. RSV was calculated as the ratio of the socket dimensions at each follow-up to the socket dimensions at baseline. Both the studies $^{28,33}$ used RSV evaluation at 7th, 14th, and 21st day of postextraction follow-up. Comparisons between values relative to the experimental and control sides showed better healing and faster socket closure for the side treated with PRGF, with differences statistically significant at day 7 and borderline at day 14. Because no other included study used this parameter, its relevance is limited.

One study carried out radiological assessment using cone-beam computerized tomographical analysis. ${ }^{27}$ The study claimed to have higher $(P<.001)$ percentage of regenerated sockets (96.7\%), higher $(P<.001)$ regenerated socket volume $(96.5 \pm 8.0 \%)$, higher $(P<$ .001) radiodensity (Hounsfield unit) of bone formed $(450.0 \pm 106.7)$, and faster bone formation at the postextraction sites treated with PRGF than at the control sites. The study also reported higher new bone formation $(P<$.049) under histomorphometric analysis in the sites 


\begin{tabular}{|c|c|c|c|c|c|c|c|c|}
\hline \multirow[b]{2}{*}{ Study } & \multirow[b]{2}{*}{$\begin{array}{l}\text { Study } \\
\text { design }\end{array}$} & \multirow[b]{2}{*}{$\begin{array}{c}\text { Patients } \\
\text { (N) }\end{array}$} & \multirow[b]{2}{*}{$\begin{array}{c}\text { Age, mean } \\
\text { (range) }\end{array}$} & \multicolumn{2}{|c|}{ Teeth (n) } & \multicolumn{2}{|c|}{ Intervention } & \multirow[b]{2}{*}{ Follow-up } \\
\hline & & & & Test & Control & Test & Control & \\
\hline $\begin{array}{l}\text { Anitua et al., } \\
2015^{27}\end{array}$ & $\mathrm{RCT}$ & 60 & $\begin{array}{l}\text { T: NR }(29-74) ; \\
\text { C: NR }(18-67)\end{array}$ & 36 & 24 & PRGF & None & $10-12$ wks \\
\hline $\begin{array}{l}\text { Cocero et al., } \\
2015^{32}\end{array}$ & RCT & 120 & NR $(6-78)$ & 98 & 106 & PRGF & Fibrin glue & $1 \mathrm{wk}$ \\
\hline $\begin{array}{l}\text { Mozzati et al., } \\
2014^{28}\end{array}$ & $\begin{array}{l}\mathrm{RCT} \\
(\mathrm{sm})\end{array}$ & 34 & $62.7 \pm 12.2(\mathrm{NR})$ & 34 & 34 & PRGF & None & 3 wks \\
\hline $\begin{array}{l}\text { Mozzati et al., } \\
2014^{33}\end{array}$ & $\begin{array}{l}\text { CCT } \\
(\mathrm{sm})\end{array}$ & 20 & $63 \pm 8$ (NR) & 57 & 57 & $\begin{array}{l}\text { PRGF in } \\
\text { irradiated } \\
\text { area }\end{array}$ & $\begin{array}{c}\text { None in } \\
\text { nonirradiated } \\
\text { area }\end{array}$ & 3 wks \\
\hline $\begin{array}{l}\text { Farina et al., } \\
2013^{30}\end{array}$ & ССТ & 28 & $55.2(34-74)$ & 18 & 18 & PRGF & None & $\begin{array}{c}4-6 \text { wks } \\
(T 1=1 \mathrm{~m}) \\
7-10 \mathrm{wk} \\
(T 2=2 \mathrm{~m})\end{array}$ \\
\hline $\begin{array}{l}\text { Haraji et al., } \\
2012^{29}\end{array}$ & $\begin{array}{l}\text { CCT } \\
(\mathrm{sm})\end{array}$ & 40 & $22.1 \pm 1.7(18-45)$ & 40 & 40 & PRGF & None & Up to $7 \mathrm{~d}$ \\
\hline $\begin{array}{l}\text { Mozzati et al., } \\
2010^{34}\end{array}$ & $\begin{array}{l}\mathrm{RCT} \\
(\mathrm{sm})\end{array}$ & 16 & $22.5(18-35)$ & 16 & 16 & PRGF & No PRGF & Up to $1 \mathrm{wk}$ \\
\hline $\begin{array}{l}\text { Anitua, } \\
1999^{25}\end{array}$ & $\mathrm{RCT}$ & 20 & $\begin{array}{l}\text { T- } 41(35-55) \\
\text { C- } 42(38-54)\end{array}$ & 10 & 10 & $\mathrm{PRGF} \pm \mathrm{ABG}$ & $A B G$ & 10 to $16 \mathrm{wks}$ \\
\hline
\end{tabular}

ABG, autogenous bone graft; $C$, control group; $C C T$, controlled clinical trial; NR, not reported; PRGF, plasma rich in growth factors; RCT, randomized clinical trial; sm, split-mouth; T, test group.

with PRGF (63.1 $\pm 13.8 \%)$ than that in control sites $(35.6 \pm 35.3 \%) .{ }^{27}$ Histologic analysis showed better bone quality in biopsies from sites treated with PRGF than in those from control sites. ${ }^{25}$

On the contrary, one study reported that the PRGF-treated group did not show any enhancement in early (4 and 8 weeks) bone deposition in comparison with the control group. $^{30}$

\section{Soft-tissue Healing}

Better epithelialization was seen in the sites treated with PRGF. Epithelialization was rather rapid and excellent compared with that in control sites. ${ }^{25}$ The measurement of the thickness of the epithelial layer indicated a thicker layer in the sockets treated with PRGF. The thickness of keratinized gingiva (140.6 $\mu \mathrm{m}$; 95\% Cl: 70.41-210.81; $P<$ .038) was higher in the PRGF group than that in the control group. ${ }^{27}$
In diabetic subjects, soft-tissue healing was significantly faster and better with the use of PRGF at test sites. ${ }^{28}$ The difference between the healing index scores was found to be highly significant at 3,7 , and 14 days $(P<.05)$. However, at the end of 21 days, the healing index scores were pretty similar and not significant $(P=.33)$ in both PRGF $(4.0 \pm 0.2)$ and control groups $(4.1 \pm 0.4) .{ }^{28}$

\section{Risk of Bias}

The RoB summary is presented in Figure 2. Four studies were classified as having a low RoB, ${ }^{25,27,29,32}$ two as having a medium risk, ${ }^{28,33}$ and two as having a high RoB. ${ }^{30,34}$

\section{DISCUSSION}

The aim of this systematic review was to assess the clinical studies that evaluated the effect of adjunctive use of PRGF in postextraction sites and critically appraise the same in terms of the listed primary and secondary outcomes. A total 
The Journal of EVIDENCE-BASED DENTAL PRACTICE

\begin{tabular}{|c|c|c|c|c|}
\hline Study & Teeth treated & $\begin{array}{l}\text { Postsurgical } \\
\text { complications }\end{array}$ & Study outcomes & Effect of PRGF \\
\hline $\begin{array}{l}\text { Anitua et al., } \\
2015^{27}\end{array}$ & $\begin{array}{l}\text { Mandibular molar } \\
\text { (1st, 2nd, and 3rd) }\end{array}$ & $\begin{array}{c}1 \text { PRGF/1 CTRL } \\
\text { (tumefaction); } 0 \\
\text { PRGF/O CTRL } \\
\text { (infection) }\end{array}$ & $\begin{array}{l}\text { 1. Percentage of } \\
\text { regenerated sockets. } \\
\text { 2. Percentage regenerated } \\
\text { volume, bone density; } \\
\text { pain; soft-tissue healing } \\
\text { score; inflammation score; } \\
\text { histomorphometric } \\
\text { analysis-percentage of } \\
\text { new bone formation; } \\
\text { keratinized gingival } \\
\text { thickness }\end{array}$ & $\begin{array}{l}\text { PRGF-treated sites } \\
\text { enhanced hard- and soft- } \\
\text { tissue healing of sockets } \\
\text { with better epithelialization } \\
\text { and increased thickness of } \\
\text { keratinized epithelium with } \\
\text { the absence of } \\
\text { inflammation. The sites } \\
\text { also presented with almost } \\
\text { negligible postoperative } \\
\text { pain. }\end{array}$ \\
\hline
\end{tabular}

Cocero et al., $\quad$ Molar, premolar, $\quad 2$ PRFG/3 Number of complications; $2015^{32}$ canine, incisor NR Mozzati et al., $2014^{28}$
CTRL (severe secondary bleeding) bleeding rate after 7-day follow-up period

NR

NR

1. Residual socket volume; pain; healing index, and
PRGF works as well as fibrin glue as a local hemostatic agent to control for bleeding after extraction. postsurgical complications

2. Patient satisfaction; effects of smoking habits,

HA1C, EODS, and

glycemia on socket reduction.

PRGF application after extraction improved the healing process in diabetic patients by accelerating socket closure

(epithelialization) and tissue maturation, proving the association between PRGF use and improved wound healing in diabetic patients.

\begin{tabular}{|c|c|c|c|}
\hline $\begin{array}{l}\text { Mozzati et al., } \\
2014^{33}\end{array}$ & $\begin{array}{l}\text { Bilateral similar } \\
\text { teeth (all types) }\end{array}$ & $\begin{array}{l}0 \text { PRGF/2 CTRL } \\
\text { (bone exposure } \\
\text { with soft-tissue }\end{array}$ & $\begin{array}{l}\text { Residual socket volume; } \\
\text { pain; healing index, and } \\
\text { postsurgical complications }\end{array}$ \\
\hline
\end{tabular}
effective in the
PRGF proved to be management of patients with a history of head and neck radiotherapy, accelerating and fostering mucosal healing and avoiding postextraction bone exposures.

PRGF-treated group did not show any enhancement in early (4 and 8 weeks)

bone deposition compared with the control group.

The application of PRGF may significantly reduce the incidence of $\mathrm{AO}$ or its associated pain and may accelerate healing. The prophylactic use of PRGF after third-molar extraction may be suggested especially in the patients at risk of $A O$. 


\begin{tabular}{|c|c|c|c|c|}
\hline Study & Teeth treated & $\begin{array}{l}\text { Postsurgical } \\
\text { complications }\end{array}$ & Study outcomes & Effect of PRGF \\
\hline $\begin{array}{l}\text { Mozzati et al., } \\
2010^{34}\end{array}$ & $\begin{array}{l}\text { Impacted } \\
\text { mandibular } \\
\text { third molars }\end{array}$ & NR & $\begin{array}{l}\text { Inflammatory cytokines } \\
\text { (real-time PCR): IL-1b, IL-6, } \\
\text { IL-10, TGF- } \beta 2, \text { BMP-2, } \\
\text { BMP-4; clinical parameters } \\
\text { and pain; facial swelling }\end{array}$ & $\begin{array}{l}\text { Postoperative pain and the } \\
\text { swelling, measured at all } \\
\text { experimental times, were } \\
\text { reduced in the presence of } \\
\text { PRGF. The cytokine profile } \\
\text { in the PRGF was favorable } \\
\text { for enhanced and } \\
\text { unprecedented healing }\end{array}$ \\
\hline Anitua, $1999^{25}$ & All types & 1 PRGF/1 CTRL & $\begin{array}{c}\text { Biopsy and histological } \\
\text { analysis }\end{array}$ & $\begin{array}{c}\text { No negative effect has } \\
\text { been found in the use of } \\
\text { PRGF. Better } \\
\text { epithelialization and } \\
\text { osseous regeneration of } \\
\text { mature bone has been } \\
\text { found in a larger quantity } \\
\text { and quality than in control } \\
\text { areas. }\end{array}$ \\
\hline
\end{tabular}

$\mathrm{AO}$, alveolar osteitis; CTRL, control; NR, not reported; PRGF, plasma rich in growth factors; TGF- $\beta$, transforming growth factor beta.

Table 3. List of excluded studies with reasons for exclusion.

Excluded study Reason for exclusion

King et al., $\quad$ PRGF used in postextraction sites with $2018^{35} \quad$ alveolar osteitis

Ntounis et al., Use of PRP as the experimental group $2015^{36}$

Geurs et al., Use of PRP as the experimental group $2014^{37}$

Mozzati et al.,

Case-control study in patients on $2011^{38}$ intravenous bisphosphonate therapy; the occurrence of bisphosphonaterelated osteonecrosis of the jaw was the only outcome reported.

\section{Anitua et al., \\ Case series}

$2015^{39}$

Case report

Nazaroglou et al., $2009^{40}$

Anitua, $2001^{41}$

Report of two cases

PRGF, plasma rich in growth factors. of 8 clinical trials were included and analyzed in this review. Most of the studies were judged as having a medium to high quality based on the criteria set for the RoB assessment. The lack of at least 2 studies with similar data set for any outcome variables prevented us from carrying out a standard meta-analysis and presenting the results through a forest plot. However, the qualitative analysis was rigorously performed to get the best conclusion about the efficacy of the adjunctive use of PRGF in postextraction sites.

One study ${ }^{29}$ used $\mathrm{AO}$ as the primary outcome and reported that there was significantly lower incidence of $A O$ in the sites treated with PRGF than in control sites. Indeed, very few studies reported adverse events or postsurgical complications, such as tumefaction, infection, and bleeding, in the postextraction sites treated with PRGF at the end of follow-up (Table 2). Although it was not possible to perform a quantitative evaluation regarding the various complications, the qualitative synthesis proved to be in favor of using PRGF in postextraction sites to lower the incidence of postsurgical complications. One controversial question is regarding the feasibility of using autologous hemocomponents when the subjects are affected by hematological diseases. The study that recruited the subjects with blood disorders, for example, coagulopathies and thrombocytopenia, in need of extraction suggested that PRGF can represent an effective
731

732

733

734

735

736

737

738

739

740

741

742

743

744

745

746

747

748

749

750

751

752

753

754

755

756 
Table 4. Postoperative pain outcomes.

\begin{tabular}{|c|c|c|}
\hline Study & $\begin{array}{l}\text { Study } \\
\text { design }\end{array}$ & Postoperative pain outcomes \\
\hline $\begin{array}{l}\text { Anitua } \\
\text { et al., } \\
2015^{27}\end{array}$ & $\mathrm{RCT}(\mathrm{P})$ & $\begin{array}{l}\text { The postoperative pain was } \\
\text { almost absent in the PRGF- } \\
\text { treated sites, having the } \\
\text { scores of } 0.17 \text { and } 0.00 \text { at day } \\
3(P<.001) \text { and day } 7 \\
(P<.03) \text {, respectively, } \\
\text { compared with that in control } \\
\text { sites. There was a highly } \\
\text { statistical difference between } \\
\text { the two. }\end{array}$ \\
\hline
\end{tabular}

\begin{tabular}{|c|c|c|}
\hline $\begin{array}{l}\text { Mozzati } \\
\text { et al., } \\
2014^{28}\end{array}$ & $\begin{array}{l}\mathrm{RCT} \\
\text { (SM) }\end{array}$ & $\begin{array}{l}\text { VAS score for postoperative } \\
\text { pain was similar in both sides, } \\
\text { dropping to zero after } 4 \text { days. }\end{array}$ \\
\hline $\begin{array}{l}\text { Mozzati } \\
\text { et al., } \\
2014^{33}\end{array}$ & $\begin{array}{l}\text { CCT } \\
\text { (SM) }\end{array}$ & $\begin{array}{c}\text { VAS score for postoperative } \\
\text { pain dropped to zero at day } 4 \\
\text { in PRGF-treated sites } \\
\text { compared with control sites } \\
\text { (at day 6). }\end{array}$ \\
\hline
\end{tabular}

\begin{tabular}{|c|c|c|}
\hline $\begin{array}{l}\text { Haraji } \\
\text { et al., } \\
2012^{29}\end{array}$ & $\begin{array}{l}\text { CCT } \\
\text { (SM) }\end{array}$ & $\begin{array}{l}\text { The VAS score for } \\
\text { postoperative pain intensity } \\
\text { was constantly lower in the } \\
\text { PRGF group than that in } \\
\text { control sites at all observation } \\
\text { times but achieved } \\
\text { significance at the end of the } \\
\text { 4th day ( } 1.69 \text { vs } 2.19 \text { ). }\end{array}$ \\
\hline
\end{tabular}

Mozzati RCT VAS score for postoperative et al., (SM) pain for PRGF-treated sites $2010^{34}$ $(0.19 \mathrm{~cm})$ was significantly lower than that for control sites $(0.49 \mathrm{~cm})$, suggesting $61.22 \%$ reduction at the end of 7 days.

CCT, controlled clinical trial; PRGF, plasma rich in growth factors; RCT, randomized clinical trial; VAS, visual analog scale.

local hemostatic agent similar to fibrin glue, controlling the incidence of severe secondary bleeding. ${ }^{32}$

Proper hard- and soft-tissue healing are the predictable outcomes to evaluate the success of alveolar socket preservation. In this review, six studies assessed the pattern of hard-tissue healing at different time points and with different outcomes: socket depth/dimension reduction, percentage of sockets with regenerated bone, bone density, and histologic and histomorphometric parameters. ${ }^{25,27-30,33}$ The variability of assessment methods for evaluating hardtissue healing in the different studies did not allow for quantitative evaluation of the effect of PRGF on such
Figure 2. Risk of bias summary.

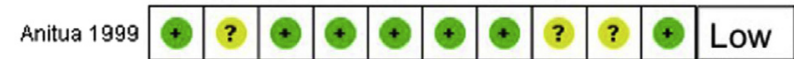

\begin{tabular}{|c|c|c|c|c|c|c|c|c|c|c|c|}
\hline \multirow[b]{2}{*}{ Anitua 2015} & & & & & & & & & & & \multirow[b]{2}{*}{ ow } \\
\hline & 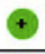 & 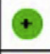 & + & $\bullet$ & + & + & + & $?$ & $\oplus$ & + & \\
\hline Cocero 2015 & $\oplus$ & $?$ & $\bullet$ & $\bullet$ & $\bullet$ & + & 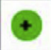 & $?$ & $?$ & + & Low \\
\hline Farina 2013 & $?$ & $?$ & (4) & O & ๑ & 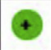 & $\theta$ & 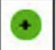 & (2) & $\theta$ & High \\
\hline Haraji 2012 & $?$ & $?$ & 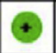 & 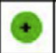 & + & + & 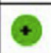 & + & + & + & Low \\
\hline Mozzati 2010 & $?$ & $\theta$ & $?$ & 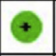 & $?$ & + & + & 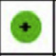 & $\theta$ & + & High \\
\hline Mozzati 2014 & $\oplus$ & + & 0 & + & 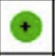 & + & $?$ & $\oplus$ & 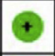 & $?$ & Med \\
\hline Mozzati 2014 & $?$ & $?$ & O & $\bullet$ & $\bullet$ & $\odot$ & $\odot$ & 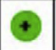 & 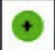 & + & Med \\
\hline
\end{tabular}

outcomes. Nevertheless, the trend of the studies suggested 841 a positive effect of PRGF because most of them concluded that there is evidence of potential of PRGF in effective hardtissue regeneration, in terms of newly formed bone quality and quantity.

On the other hand, one of the included studies ${ }^{30}$ reported that the effect of PRGF on new bone formation/deposition was rather nonbeneficial. That study concluded that the PRGF-treated group did not show any enhancement in early (4 and 8 weeks) bone deposition in comparison with the control group. However, the study was found to have strong biases and was critically questioned on its experimental design. $^{42}$ In fact, in that study, all the subjects who had smoking habits and all those with teeth extracted due to periodontal disease were included in the PRGF group (representing more than $50 \%$ of cases: 6 out of 11), whereas no patient with a history of periodontitis or smoking habits was allocated to the control group. ${ }^{30}$ A question was also raised regarding the protocol of allowing the sites with PRGF to heal by secondary intention as in this article; it was unclear if sutures were systematically applied or not. ${ }^{30}$ In fact, even though adhesive properties of PRGF should keep it in place, there exists a chance of dislodgement or
843

844

845

846

847

848

849

850

851

852

853

854

855

856

857

858

859

860

861

862

863

864 
escaping of the PRGF gel into the oral cavity if not secured by R4 sutures, leading to noneffectiveness of PRGF. ${ }^{42}$ Moreover, the study did not mention the sites of extraction, if not bilateral or one tooth/arch that could result in crossover effect. The high number of biases made the results of this study unreliable and might be a reason for its findings being not in line with the other studies.

Indeed, also in other included studies, there was no explicit mention of the application of sutures to secure PRGF in situ at the end of the surgical procedure, which may be considered a sort of bias for these studies. ${ }^{25,28,29,33}$

Better epithelialization and enhanced socket healing were reported in 4 studies. ${ }^{25,27,28,33}$ Keratinized gingiva formed on the sites of healing sockets was significantly thicker in the PRGF group. The inflammation was found to lesser in the sites treated with PRGF and resolved faster. This finding is in concordance with findings of other studies using different platelet concentrates such as PRP, which may limit inflammation, interacting with macrophages to improve tissue healing and regeneration, ${ }^{43}$ promote new capillary growth, ${ }^{44}$ and accelerate epithelialization ${ }^{45}$ in chronic wounds. It was also found that the PRGF had an advantage in enhancing soft-tissue healing and reducing the extent of inflammation in subjects with delayed healing in case of diabetes mellitus. ${ }^{28}$ The dissolution time of PRGF in vivo has never been evaluated, but the kinetics of growth factor delivery by PRGF has been studied in vitro. ${ }^{46}$ After a rapid initial release of platelet granules' content in the first hour, the gel-like PRGF kept on releasing growth factors up to 8 days of incubation. ${ }^{46}$ After that time, almost $30 \%$ of the growth factor amount was retained in the fibrin matrix. Another in vitro study, performed under different experimental conditions, reported that the PRGF membrane, after a slow but continuous release of growth factors, dissolves within 5 days of incubation. ${ }^{47}$ Of course, the in vivo kinetics release and matrix dissolution might be different. Nevertheless, the sustained release of growth factors could explain the reported beneficial effects of PRGF on soft tissues in the first week after extraction. On the other hand, it is still controversial if PRGF may have a stimulating effect on bone tissue because of the slow healing of the latter. However, it may be hypothesized that the fast and predictable softtissue closure at postextraction sites observed with PRGF may also have a positive protective effect for the healing of underlying hard tissues, triggering the bone-healing process and controlling the incidence of postoperative contamination of the site and of postoperative discomfort.

Regarding the effect of the adjunct of PRGF on postoperative quality of life, no quantitative evaluation through metaanalysis could be performed because of differences in methods of assessing the outcome and in reporting the results. In fact, regarding pain evaluation using a visual analog scale, a few studies ${ }^{27,29,34}$ assessed the mean of scores achieved on a 10-point scale and others ${ }^{28,33}$ assessed the followup day at which the score drops to zero. One study reported mean values and standard deviations, ${ }^{27}$ another study only reported the values on a graph, ${ }^{34}$ and another one did not report the standard deviation. ${ }^{29}$ Two studies reported pain daily, ${ }^{27,34}$ and others reported the mean values only on selected days. ${ }^{29}$ Nevertheless, the trend of the studies evaluating quality of life was in favor of a reduction of the intensity of postoperative pain and symptoms in patients treated with the adjunct of PRGF, suggesting that the use of PRGF may be beneficial for postoperative pain control. This is in agreement with what was reported for other clinical applications such as maxillary sinus floor elevation ${ }^{48}$ and endodontic surgery. ${ }^{49}$

Finally, some limitations of this review should be acknowledged. For example, no distinction was made between studies dealing with single extraction sites and studies in which multiple extraction sites were treated, and no correlation was attempted between the effect of the treatment and other potential confounding factors, such as the socket location, the reason for extraction, and the presence and condition of the adjacent teeth and alveolar bone. Indeed, because almost no study provided individual patients' data, such correlations were unfeasible in this systematic review. It is recommended that in future studies, the individual patients' data are reported in detail to determine the weight of the aforementioned factors on the treatment outcomes.

\section{CONCLUSION}

Qualitative analysis of the studies suggested that PRGFs could represent a useful tool for improving postextraction hard- and soft-tissue healing and reducing adverse events, complications, and patients' discomfort. However, because a quantitative analysis could not be performed, the actual benefits of PRGF on healing and pain control in extraction sockets are still not quantifiable. More studies, with standardized protocols, are needed to confirm and strengthen the results of this review.

\section{REFERENCES}

1. Buchwald S, Kocher T, Biffar R, Harb A, Holtfreter B, Meisel P. Tooth loss and periodontitis by socio-economic status and inflammation in a longitudinal population-based study. J Clin Periodontol 2013;40:203-11.

2. Araújo $M G$, Lindhe J. Dimensional ridge alterations following tooth extraction. An experimental study in the dog. J Clin Periodontol 2005;32:212-8.

3. Bui $\mathrm{CH}$, Seldin EB, Dodson TB. Types, frequencies, and risk factors for complications after third molar extraction. J Am Assoc Oral Maxillofac Surg 2003;61:1379-89. 
4. Flügge T, Nelson K, Nack C, Stricker A, Nahles S. 2-Dimensional changes of the soft tissue profile of augmented and nonaugmented human extraction sockets: a randomized pilot study. J Clin Periodontol 2015;42:390-7.

5. Chan H-L, Lin G-H, Fu J-H, Wang H-L. Alterations in bone quality after socket preservation with grafting materials: a systematic review. Int J Oral Maxillofac Implants 2013;28:710-20.

6. Vittorini Orgeas G, Clementini M, De Risi V, de Sanctis M. Surgical techniques for alveolar socket preservation: a systematic review. Int J Oral Maxillofac Implants 2013;28:1049-61.

7. Vignoletti F, Matesanz P, Rodrigo D, Figuero E, Martin C, Sanz M. Surgical protocols for ridge preservation after tooth extraction. A systematic review. Clin Oral Implants Res 2012;23: 22-38.

8. Horváth A, Mardas N, Mezzomo LA, Needleman IG, Donos N. Alveolar ridge preservation. A systematic review. Clin Oral Investig 2013;17:341-63.

9. Avila-Ortiz G, Elangovan S, Kramer KWO, Blanchette D, Dawson DV. Effect of alveolar ridge preservation after tooth extraction: a systematic review and meta-analysis. J Dent Res 2014;93:950-8.

10. Willenbacher $M$, Al-Nawas B, Berres $M$, Kämmerer PW, Schiegnitz $E$. The effects of alveolar ridge preservation: a metaanalysis. Clin Implant Dent Relat Res 2016;18:1248-68.

11. Brugnami $F$, Then PR, Moroi $H$, Kabani $S$, Leone CW. GBR in human extraction sockets and ridge defects prior to implant placement: clinical results and histologic evidence of osteoblastic and osteoclastic activities in DFDBA. Int J Periodontics Restorative Dent 1999;19:259-67.

12. Yilmaz S, Efeoğlu E, Kiliç AR. Alveolar ridge reconstruction and/ or preservation using root form bioglass cones. J Clin Periodontol 1998;25:832-9.

13. Serino G, Biancu $S$, lezzi G, Piattelli A. Ridge preservation following tooth extraction using a polylactide and polyglycolide sponge as space filler: a clinical and histological study in humans. Clin Oral Implants Res 2003;14:651-8.

14. Choi H-K, Cho H-Y, Lee S-J, et al. Alveolar ridge preservation with an open-healing approach using single-layer or doublelayer coverage with collagen membranes. J Periodontal Implant Sci 2017;47:372-80.

15. Corbella S, Taschieri S, Francetti L, Weinstein R, Del Fabbro M. Histomorphometric results after postextraction socket healing with different biomaterials: a systematic review of the Literature and meta-analysis. Int J Oral Maxillofac Implants 2017;32: 1001-17.

16. Fernández RF, Bucchi C, Navarro P, Beltrán V, Borie E. Bone grafts utilized in dentistry: an analysis of patients' preferences. BMC Med Ethics 2015;16:71.

17. Darby I, Chen ST, Buser D. Ridge preservation techniques for implant therapy. Int J Oral Maxillofac Implants 2009;24:260-71.
18. Howell TH, Fiorellini J, Jones A, et al. A feasibility study evaluating rhBMP-2/absorbable collagen sponge device for local alveolar ridge preservation or augmentation. Int J Periodontics Restorative Dent 1997;17:124-39.

19. Wang L, Huang Y, Pan K, Jiang X, Liu C. Osteogenic responses to different concentrations/ratios of BMP-2 and bFGF in bone formation. Ann Biomed Eng 2010;38:77-87.

20. Panda S, Doraiswamy J, Malaiappan S, Varghese SS, Del Fabbro M. Additive effect of autologous platelet concentrates in treatment of intrabony defects: a systematic review and meta-analysis. J Investig Clin Dent 2016;7:13-26.

21. Del Fabbro $M$, Bucchi $C$, Lolato A, Corbella S, Testori $T$, Taschieri S. Healing of postextraction sockets preserved with autologous platelet concentrates. A systematic review and meta-analysis. J Am Assoc Oral Maxillofac Surg 2017;75: 1601-15.

22. Moraschini V, Barboza ESP. Effect of autologous platelet concentrates for alveolar socket preservation: a systematic review. Int J Oral Maxillofac Surg 2015;44:632-41.

23. Del Fabbro M, Bortolin M, Taschieri S. Is autologous platelet concentrate beneficial for post-extraction socket healing? A systematic review. Int J Oral Maxillofac Surg 2011;40:891-900.

24. Del Fabbro M, Corbella S, Taschieri S, Francetti L, Weinstein R. Autologous platelet concentrate for post-extraction socket healing: a systematic review. Eur J Oral Implantol 2014;7: 333-44.

25. Anitua E. Plasma rich in growth factors: preliminary results of use in the preparation of future sites for implants. Int J Oral Maxillofac Implants 1999;14:529-35.

26. Anitua E, Andia I, Ardanza B, Nurden P, Nurden AT. Autologous platelets as a source of proteins for healing and tissue regeneration. Thromb Haemost 2004;91:4-15.

27. Anitua E, Murias-Freijo A, Alkhraisat MH, Orive G. Clinical, radiographical, and histological outcomes of plasma rich in growth factors in extraction socket: a randomized controlled clinical trial. Clin Oral Investig 2015;19:589-600.

28. Mozzati M, Gallesio G, di Romana S, Bergamasco L, Pol R. Efficacy of plasma-rich growth factor in the healing of postextraction sockets in patients affected by insulin-dependent diabetes mellitus. J Am Assoc Oral Maxillofac Surg 2014;72: 456-62.

29. Haraji A, Lassemi E, Motamedi MHK, Alavi M, Adibnejad S. Effect of plasma rich in growth factors on alveolar osteitis. Natl J Maxillofac Surg 2012;3:38-41.

30. Farina R, Bressan E, Taut A, Cucchi A, Trombelli L. Plasma rich in growth factors in human extraction sockets: a radiographic and histomorphometric study on early bone deposition. Clin Oral Implants Res 2013;24:1360-8.

31. Moher D, Liberati A, Tetzlaff J, Altman DG; PRISMA Group. Preferred reporting items for systematic reviews and metaanalyses: the PRISMA statement. BMJ 2009;339:b2535. 
32. Cocero N, Pucci F, Messina M, Pollio B, Mozzati M, Bergamasco L. Autologous plasma rich in growth factors in the prevention of severe bleeding after teeth extractions in patients with bleeding disorders: a controlled comparison with fibrin glue. Blood Transfus Trasfus Sangue 2015;13:287-94.

33. Mozzati M, Gallesio G, Gassino G, Palomba A, Bergamasco L. Can plasma rich in growth factors improve healing in patients who underwent radiotherapy for head and neck cancer? A splitmouth study. J Craniofac Surg 2014;25:938-43.

34. Mozzati M, Martinasso G, Pol R, et al. The impact of plasma rich in growth factors on clinical and biological factors involved in healing processes after third molar extraction. J Biomed Mater Res A 2010;95:741-6.

35. King EM, Cerajewska TL, Locke M, Claydon NCA, Davies M, West NX. The efficacy of plasma rich in growth factors for the treatment of alveolar osteitis: a randomized controlled trial. J Am Assoc Oral Maxillofac Surg 2018;76:1150-9.

36. Ntounis A, Geurs N, Vassilopoulos P, Reddy M. Clinical assessment of bone quality of human extraction sockets after conversion with growth factors. Int J Oral Maxillofac Implants 2015;30:196-201.

37. Geurs N, Ntounis A, Vassilopoulos P, Van der Velden U, Loos BG, Reddy M. Using growth factors in human extraction sockets: a histologic and histomorphometric evaluation of short-term healing. Int J Oral Maxillofac Implants 2014;29:485-96.

38. Mozzati M, Arata V, Gallesio G, Carossa S. A dental extraction protocol with plasma rich in growth factors (PRGF) in patients on intravenous bisphosphonate therapy: a case-control study. Jt Bone Spine Rev Rhum 2011;78:648-9.

39. Anitua E, Orive G. Treatment of post-extraction defects using PRGF technology: case-series study. Ital Oral Surg 2015;9:115.

40. Nazaroglou I, Stavrianos C, Kafas P, et al. Radiographic evaluation of bone regeneration after the application of plasma rich in growth factors in a lower third molar socket: a case report. Cases J 2009;2:9134.
41. Anitua $E$. The use of plasma-rich growth factors (PRGF) in oral surgery. Pract Proced Aesthet Dent PPAD 2001;13:487-93. quiz 487-93.

42. Anitua E, Alkhraisat MH, Orive G. Rigorous methodology is the school of coherent conclusions in science. Eur J Oral Implantol 2013;6:9-11.

43. Mishra A, Woodall J, Vieira A. Treatment of tendon and muscle using platelet-rich plasma. Clin Sports Med 2009;28:113-25.

44. McAleer JP, Sharma S, Kaplan EM, Persich G. Use of autologous platelet concentrate in a nonhealing lower extremity wound. Adv Skin Wound Care 2006;19:354-63.

45. Knighton DR, Ciresi KF, Fiegel VD, Austin LL, Butler EL. Classification and treatment of chronic nonhealing wounds. Successful treatment with autologous platelet-derived wound healing factors (PDWHF). Ann Surg 1986;204: 322-30.

46. Anitua E, Zalduendo MM, Hamdan Alkhraisat M, Orive G. Release kinetics of platelet-derived and plasma-derived growth factors from autologous plasma rich in growth factors. Ann Anat 2013;195:461-6.

47. Dohan Ehrenfest DM, Bielecki T, Jimbo R, et al. Do the fibrin Architecture and leukocyte content Influence the growth factor release of platelet concentrates? An evidence-based Answer comparing a pure platelet-rich plasma (P-PRP) gel and a leukocyte- and platelet-rich fibrin (L-PRF). Curr Pharm Biotech 2012;13:1145-52.

48. Del Fabbro M, Corbella S, Ceresoli V, Ceci C, Taschieri S. Plasma rich in growth factors improves patients' postoperative quality of life in maxillary sinus floor augmentation: preliminary results of a randomized clinical study. Clin Implant Dent Relat Res 2015;17:708-16.

49. Del Fabbro M, Ceresoli V, Lolato A, Taschieri S. Effect of platelet concentrate on quality of life after periradicular surgery: a randomized clinical study. J Endod 2012;38:733-9. 